\title{
Application of Nanocomposites of Silicon Base in Ecology and Energy \\ [Kartunov S.]
}

\begin{abstract}
The article presents results from the study 1722-M /2017, conducted in the Technical University of Gabrovo, BG. A $\mathrm{Au} / \mathrm{TiO}_{2}$ composite consisting of a nanoparticle of gold $(\sim 15 \mathrm{~nm})$ in porous $\mathrm{TiO}_{2}$ is synthesized. The composite was made by applying nanoparticles $\mathrm{Au}$ first with a $\mathrm{SiO}_{2}$ layer and then coating the composite with a $\mathrm{TiO}_{2}$ layer. Applications of nanocomposites in ecology and energy are explored.
\end{abstract}

Keywords-Nanocomposites, Silicon base

\section{Introduction}

Photovoltaic solar collectors, called "solar panels" or "photovoltaic", are designed to directly convert the sunlight into an electric current. Solar panels are made from individual elements (cells) with a certain area. At present, the most common technology for making photovoltaic elements is silicon based. The materials used for the production of photovoltaic cells (PVC) are:

- monocrystalline silicon;

- polycrystalline silicon;

- thin film photoelements;

- amorphous silicon;

- mixed type.

\section{Exposition}

\subsection{Monocrystalline silicon}

The use of monocrystalline silicon and nanocomposites in the production of solar energy is one step ahead of mankind in building a more ecological existence. During processing, the crystal is cut into extremely thin discs, about $0.2 \mathrm{~mm}$ thick, from which the cells themselves are made. The precision of the crystal growth process increases its cost, making these PV-cells the most expensive. To reduce the price, some cells are made of ribbon silicon (Ribbon Silicon), which is also monocrystalline, but in the form of a thin layer. Massproduced monocrystalline cells have an efficiency of $13-18 \%$. The efficiency of the panels is always slightly lower, and in this case it is about $11-16 \%$. A typical $100 \mathrm{~cm}^{2}$ photovoltaic cell provides $1.5 \mathrm{~W}$ of power at maximum light.

\section{2. Thin film photoelements}

Based on this technology, cells of different materials are produced, which are deposited as a very thin layer on a pad. For comparison, for classical silicon elements, the thickness of the photocell is in the order of $0.2 \mathrm{~mm}$ or $200 \mathrm{~mm}$, whereas for thin film elements the thickness of the generating layer is only a few micrometers. The thickness of the layer is determined by the light absorption coefficient of a given material. If the layer is very thin, the light would pass through it without being swallowed, and therefore without generating electricity. By using thin-film technology, the cost of photoelements is greatly reduced. Classification of thin film technologies has been proposed in publications $[1,2]$. One of the main advantages of all thin-film technologies is the much smaller amount of semiconductor materials used (about 1\%) compared to the bulk technologies. For example, about $1 \mathrm{~g}$ of amorphous silicon is needed for an area of $1 \mathrm{~m}^{2}$.

\section{3. Amorphous silicon}

The main representative of the materials used for thin-film technologies is amorphous silicon (a-Si). It converts light about 40 times more efficiently than monocrystalline, allowing the use of layers up to $1 \mathrm{~mm}$ thick applied on a glass, steel or other material base. Photovoltaic cells with a flexible plastic base are also made. The typical structure of a thin film photoelement. An advantage of amorphous silicon is the significantly lower price of the PV-cell, which determines its application in mass devices calculators, garden lights and specialized ones - for example sensors. The disadvantage of amorphous silicon is the lower energy conversion factor with typical values between 5 and $7 \%$ for serial production and up to $13 \%$ in laboratory models.

Despite the simple method of producing porous, amorphous silicon, there are a number of technological tasks such as deep etching with storage of the consistency of the formed structure or the etching coefficient, methods for developing n-type patterns in two-sided etching, methods for stabilizing the properties of a strong porous layers, poor reproducibility, dependence of silicon properties on the properties of the monocrystalline discs, the absence of aggregated information on the mechanisms, materials and etching solutions personal conditions. Etching solutions where the defining stage is the chemical reaction with the surface of the 
substrate are called selective. In these, the energy of activation of the chemical reaction $\Delta \mathrm{Ea}$ is on the order of magnitude higher than the energy that determines the rate of reagent diffusion to the surface:

$\mathrm{V} \approx \mathrm{V}_{\mathrm{p}}=\left(\mathrm{N}_{\mathrm{A}}\right)^{\mathrm{a}} \cdot\left(\mathrm{N}_{\mathrm{B}}\right)^{\mathrm{b}} \cdot \exp \left(-\Delta \mathrm{E}_{\mathrm{a}} / \mathrm{RT}^{\circ}\right)$,

where NA, NB are the concentrations of the reactants; $\mathrm{a}$ and $\mathrm{b}$ - indicators equal to the coefficients in the chemical reaction equations; $\mathrm{R}$ is the universal gas constant; $\mathbf{V}_{\mathbf{p}}$ - the rate of chemical reaction. The energy of activation of the chemical reaction $\Delta \mathrm{Ea}$ depends on the non-uniformity of the substrate surface, i.e. the velocity $\mathrm{V}$ is also determined by the surface condition. The different $\mathrm{Si}$ silicon crystallographic directions have a different energy $\Delta \mathrm{Ea}$ due to the amorphous nature of the material, i.e. the rate of etching will depend both on the crystallographic orientation of the substrate and on the temperature $T^{\circ}$. By selecting the etching solution, its concentration, temperature and duration of etching can very precisely adjust the thickness of the removed layer.

\subsection{Mixed type}

The influence of composite metals on the properties of nanocomposites based on silicon structures titanium dioxide synthesized for solar collectors is explained in detail in a publication [4].

The criterion for assessing the capabilities of a cell and the material it is made of is the power conversion factor of the power flow into electrical power, better known as the efficiency factor (CPU) of the device. Monocrystalline silicon photovoltaic cells are used as a source element for standard modules for solar parks and have an efficiency of $14 \%$ to $17.7 \%$. For polycrystals, this indicator is from $10 \%$ to $14 \%$ and the material used is polycrystalline silicon. Amorphous photovoltaic cells, also called thin films, are made of amorphous silicon and have an EQ of no more than $10 \%$.

\section{III. observations \\ Experimental}

3.1. Monocrystalline photovoltaic panels

Monocrystalline photovoltaic panels are among the most effective and reliable elements for producing electricity from the sun. Each module is made of a single silicon crystal and is much more efficient, although more expensive, than the new polysilicon or thin-film PV panel technology. The monocrystalline photovoltaic panels, as their name suggests, differ from the others in that they use single, very pure silicon crystal. A process very similar to that used for making semiconductors is used. Unlike microelectronics, however, solar cells in terms of structural imperfections are less responsible. Silica, quartz sand or quartz sand are placed in an electric arc furnace. Under the influence of heat, carbon dioxide and molten silicon are produced. This elementary process produces silicon with an impurity content of $1 \%$. Although this product is used in many industries to make photovoltaic panels, a much cleaner material is needed. This is achieved by passing a silicon in the form of a stick through the heated zone several times in the same direction. This procedure pulls the impurities to one end with each stroke. At some point silicon is considered clean and the end where the impurities have accumulated is cut off. Then the silicon crystal the embryo is placed in Chohralsky's apparatus, where it is melted in molten polycrystalline silicon [3]. A small amount of pine is added. The fetal crystal rotates while it is pulled. From the silicon block thin lines are cut and are stamped one after the other and placed in a furnace. There, they are heated slightly by the temperature required to melt the silicon (temperature $1410^{\circ} \mathrm{C}$ ) in the presence of gaseous phosphorus. Phosphorus atoms penetrate into silicon, which is more porous because it is almost liquid. The temperature and time of the process are carefully monitored to ensure uniform welding and to the proper depth.

\subsection{Nanocomposite solutions in search of higher efficiency}

Nanocomposite materials used in the solar cell can significantly improve its effectiveness. The highest efficiency factor gives the $\mathrm{CNT}-\mathrm{TiO}_{2}-\mathrm{SiO}_{2}$ composite. Its use allows the solar cell to work better by $31.25 \%$. The use of nanocomposites has significant benefits because it reduces manufacturing costs as it is a low-temperature process similar to printing, unlike traditional high-temperature vacuum processes used in the production of conventional solar cells. The nanocomposite layer can be applied by means of flexible rollers.

3.3. Anti-reflection coating of the solar cell Nanocomposite coatings in turn increase efficiency by allowing more light to be absorbed. Silicon has a highly reflective surface that repels nearly $30 \%$ of the falling light. This reflects the efficiency of the PVpanel. By reducing reflexivity, a better absorption of energy is achieved. This coating reduces photons that return to the atmosphere and thus improves efficiency. A thin layer of antireflective material such as $\mathrm{SiO}_{2}, \mathrm{SiN}, \mathrm{SiON}$ and $\mathrm{TiO}_{2}$ are superimposed on the surface of the solar cell. The chemicals used for the nanocomposite coating are aluminum isopropoxide, carbon nanotubes, zinc sulphide, and a combination of silver nitrate and aluminum isopropoxide. 
Fig. 1. A polymeric solar cell (a) with a top layer removed and (b) a CNT- $\mathrm{TiO}_{2}$ coating

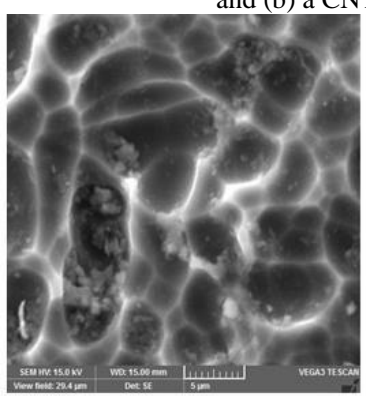

(a)

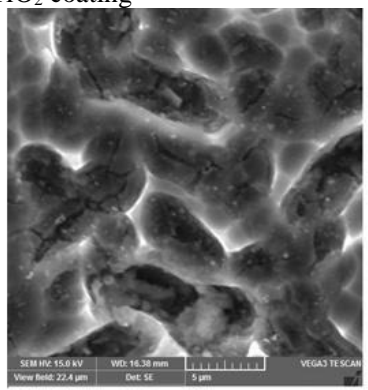

(b)
Table 1. Surveillance of coated anti-reflective material and open solar cell

\begin{tabular}{|c|c|c|c|}
\hline $\begin{array}{c}\text { S } \\
\text { № }\end{array}$ & Resistance, $\Omega$ & $\begin{array}{c}\text { Power of } \\
\text { uncovered } \\
\text { cell, mW }\end{array}$ & $\begin{array}{l}\text { Power } \\
\text { from } \\
\text { CNT } \\
\text { covered } \\
\text { cell, } \mathrm{mW}\end{array}$ \\
\cline { 2 - 4 } & & 49,5 & 72 \\
\hline 2 & 50 & 44,17 & 61,8 \\
\hline 3 & 60 & 40 & 54,57 \\
\hline 4 & 70 & 35,2 & 50,76 \\
\hline 5 & 80 & 32 & 43,7 \\
\hline 6 & 90 & 29,7 & 39,9 \\
\hline 7 & 100 & 19,5 & 38 \\
\hline 8 & 200 & 14,45 & 19,8 \\
\hline 9 & 300 & 10,5 & 12,4 \\
\hline 10 & 400 & 7,2 & 10 \\
\hline 11 & 800 & 3,6 & 5 \\
\hline 12 & 1000 & 2,7 & 4 \\
\hline 13 & 2000 & 0,18 & 0,2 \\
\hline & & & \\
\hline
\end{tabular}

Fig. 2. V-A characteristic

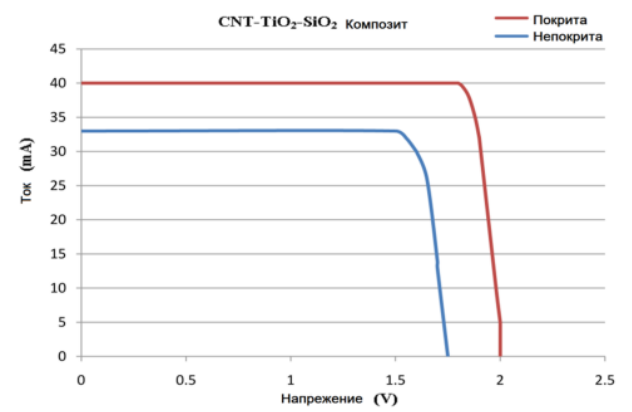

The nanocomposites are prepared from a solution of an appropriate amount of titanium isopropoxide and tetraethoxysilane in pure alcohol, which are basic materials due to their adhesive properties and refractive index. The solution is then placed in an ultrasonic bath. Various materials such as CNT, ZnS, aluminum isopropoxide are added to the solution. This solution was then stirred for 30 minutes, with a magnetic stirrer.

The coating of the nanocomposite coating solar cell comprises the steps of:

1. On the commercially available panel, the top polymeric coating is removed.

2. The surface of the solar cell is cleaned with alcohol and HF to remove the obsolete layer. 3 . Cover the solar cell with the reconstituted solution. This coating may also be applied by means of a nebulizer to obtain uniformity.

4. After coating, the panel is dried under a tungsten lamp for about half an hour. It can then be cooled to room temperature and used as intended.

Figure 1 shows scanned images of an electron microscope of a polymeric silicon solar cell on which the top layer was removed and of a CNT nanocomposite coating solar cell. These tests help to understand structural modifications after coating. It is clear that the uncovered cell has an etched surface with no polymer particles uncovered, whereas the precipitation of structures on the inner surface of the etched silicon is observed on the antireflection coated coating. Increasing efficiency can be understood by the volt-ampere characteristic as a function of resistance. For this experiment, a solar cell with a characteristic of 2 volts of 100 milliampers is placed under sunshine between 12 and 13 hours. The power obtained is described in Table 1 as the voltage is taken on the $\mathrm{X}$ axis and the $\mathrm{Y}$-axis current. Only at the appropriate resistance bound through the cell an optimal current flow will be generated. With these resistance values across the cell, the maximum available electrical energy will be delivered to the resistor.

\section{Conclusion}

The nanostructured systems detect a potential opportunity for creating and using renewable energy devices with much less waste generation and separation. The physico-mechanical properties of silicon-based nanocomposites depend on the materials incorporated in the nanocomposites. In study $1722 \mathrm{M} / 2017$ of Technical University of Gabrovo, an $\mathrm{Au} / \mathrm{TiO}_{2}$ composite consisting of a nanoparticle of gold $(\sim 15 \mathrm{~nm})$ in porous $\mathrm{TiO}_{2}$ was synthesized. The composite was made by applying nanoparticles $\mathrm{Au}$ first with a $\mathrm{SiO}_{2}$ layer and then coating the composite with a $\mathrm{TiO}_{2}$ layer. 
Proc. of the Sixth Intl. Conf. Advances in Civil, Structural and Mechanical Engineering - CSM 2018 Copyright $(\odot$ Institute of Research Engineers and Doctors, USA. All rights reserved.

ISBN: 978-1-63248-150-4 doi: 10.15224/978-1-63248-150-4-50

\section{REFERENCES:}

1. Kartunov S., Boev B., D. Angelova, CLASSIFICATION OF THIN FILM AND ULTRA THIN FILM DEPOSITION METODS-1, Roma, IRED, 5. International Conference "AMRE", 2017, ISBN 978-1-63248-123-8, p. 37-38

2. Картунов С., Б. Боев, CLASSIFICATION OF THIN FILM AND ULTRA THIN FILM DEPOSITION METODS-2, Минск, 32 МНТК „Металообработка”, 2017, УДК 539.3, стр.123-125

3. Къртунов С., Технологични основи в мехатрониката, микро- и наносистемната техника, (учебник-монография), Габрово, УИ „В. Априлов”, 2012 година, ISBN 978-954-683482-9 (in Bulgarian)

4. Kartunov S., Effect of noble metals on the properties of nanocomposites based on silicon structures and titanium dioxide, synthesized for solar collectors, Zlatibor, 17. Int.Conference "RADMI", 2017, ISBN 978-86-6075-062-6, p. 155

\section{About the authors}

Prof. Dr-Ing. Stefan Kartunov, TU Gabrovo, Bulgaria, Hadji Dimitar Str. 4, Department MU, Mechanical Engineering

Tel.++35966827365, Lab. Micro- and Nanotechnologies

Research interests: Technological process of microand nano elements, CAD/CAM/CAE-studies, simulations and animations before/in the production 